\title{
MODELO DE ENSINO PARA COMPETÊNCIA APLICADO À ENFERMAGEM*
}

\author{
Márcia Caron-Ruffino**
}

\begin{abstract}
RESUMO - A autora, partindo do princípio que é necessário ao docente conscientizar-se das determinantes sociais que interferem na educação, incita-o, por isso mesmo a desenvolver sua competência no ensino exercendo assim sua função política. Dado que o modelo de ensino para o domínio descrito por Benjamin Bloom (cognitivista) foi pouco explorado na área biológica, resolve testá-lo no campo de ensino de enfermagem.
\end{abstract}

ABSTRACT - The author, based on the principle that a teacher should be aware of the social determinants that interfere with education, recommends - in consequence - that he should develop his teaching competence and this way he must perform his political function. Since the teaching model for mastery described by Benjamin Bloom (cognitive) has been little explored in the biological area, the author decided to test it in the field of nursing teaching.

\section{INTRODUÇÃO}

Nesse trabalho propusemo-nos a utilizar o modelo de ensino para competência de Bloom no nosso quotidiano na escola.

A hipotese de trabalho foi de que a utilização da abordagem de ensino para a competência (com os acertos pós-estudo-piloto) aumentaria o rendimento (expresso em escores) do ensino até então obtido em anos anteriores, e o objetivo foi testar a hipotese referida.

Foi aplicado o modelo de ensino proposto por Benjamim Bloom e baseado na aprendizagem para o domínio. A população era constiturda de alunos matriculados no $2^{\circ}$. ano de graduação.

$\mathrm{O}$ número de alunos foi de 72 , divididos em 2 grandes grupos, sendo o $1^{\circ}$ grupo de 42 e o $2^{\circ}$. grupo de 30. Para um destes grupos, foram ministradas aulas teoricas e este foi, por sua vez, subdividido em 4 (quatro) sub-grupos para atividades práticas de campo.

Essa população se compunha de alunos quase que exclusivamente do sexo feminino $(97 \%)$, com idade média de 20 anos, que já tinham um saber básico, referente a conhecimentos e técnicas adquiridas em disciplina pré-requisito para a entrada no programa proposto. Este, como vimos, se inicia pela seleção de organização dos objetivos de ensino, e nesse processo foi utilizada a taxionomia de Bloom que divide os objetivos em três domínios: cognitivo, afetivo e psicomotor; neste trabalho optamos pelo desenvolvimento do domínio cognitivo, que abrange memória, pensamento e solução de problemas (BLOOM et alii, 1972).
Como primeiro passo, efetuamos, anteriormente ao curso, a elaboração e discriminação de 26 objetivos da categoria de evocação ou conhecimento memorizado, 17 de aplicação do conhecimento, e 14 de síntese das situações nas quais o conhecimento é aplicado, bem como atividades de aprendizagem e instrumentos de avaliação relativos a cada tipo de objetivo (CARON-RUFFINO, 1985).

Após a discriminaação desses objetivos, utilizamos o plano de unidade para a consecução dos objetivos de conhecimento; outro plano de unidade, a ser desenvolvido para atingir os objetivos de aplicação; e em terceiro plano de unidade, que proporciona as condições para que os alunos dominem os objetivos de sintese. (CARON-RUFFINO, 1986).

Os objetivos de conhecimento foram propostos para a classe toda, ou seja, os 72 alunos matriculados no 4. semestre: os objetivos de aplicação e síntese foram propostos ao grupo de 42 alunos que passaram, no estágio de campo.

Acreditamos que um aspecto importante para se conseguir atingir os objetivos de ensino é o planejamento, o qual deve ser claro, detalhado, baseado em elementos concretos sobre a realidade em questão. Esse planejamento conforme CASAGRANDE (1973) "parte de uma idéia, entendida como objetivo a alcançar, que traduz resultados definidos como produtos ". Esse alcance será atingido somente através de ação racional, composta de recursos de trabalho, recursos financeiros e tempo suficiente para a sua efetivação. Entendemos por recursos os meios utilizados para permitir a ocorrência do desempenho desejąo

* Resumo da Tese de Doutoramento em Enfermagem

* Docente da Escola de Enfermagem de Ribeirão Preto, USP. 
e por recursos de trabalho, os humanos, materiais e didáticos; os recursos financeiros são os custos; e o tempo necessário para ef etivação é o cronograma de trabalho. Segundo ROSCHKE (s.d.), a elaboração desse cronograma pode ser considerada como uma das primeiras etapas de organização de um curso este possibilitará ao professor plane jar suas atividades, considerando as possíveis altemativas em função da variável tempo e, conseqüentemente, constitui um guia para o professor e como tal deve ser utilizado.

Os planos de ensino que efetuamos para a unidade de assistência de enfermagem a pacientes de clinica médica coincidem com as afirmações de CASAGRANDE (1985), de que é imprescindivel que as intenções do educador sejam claramente organizadas em proposições que descrevam as realizações a serem alcançadas pelo aprendiz, ao final de várias etapas da implementação do ensino - " "essas proposições têm sido denominadas objetivos educacionais e constituem as metas ou finalidades gerais a que se orientam as diferentes propostas curriculares".

Utilizamos este referencial teórico para a elaboração dos objetivos, para a seleção, operacionalização e inclusão dos mesmos no planejamento didático da unidade; procuramos seguir informaçōes e sugestões de FONTANIVE (1980), que aborda alguns aspectos essenciais sobre a formulação de objetivos, de modo a torná-los claros, unívocos e utilizáveis no desenvolvimento do ensino.

Ao darmos continuidade ao plano selecionamos o conteúdo, pois a $2^{\circ}$ condição para o aprendizado é de que haja "indicação do que deve ser aprendido". $O$ ensino deve apresentar claramente ao aprendiz aquilo que se espera que ele aprenda - é a chamada matéria de ensino - acumulada e organizada pelo grupo social a que pertence o educando, devendo ser compreendida e dominada pelos alunos, de modo a ser incorporada à sua experiência pessoal, podendo ser por eles reelaborada e aperfeiçoada. Esta matéria está relacionada ao conteúdo instrucional ou conteúdo programático.

Supōe-se que o educador em enfermagem, ao levar a efeito sua tarefa, tenha sempre alguma (s) intenção (ões) e para concretização da (s) mesma (s), o que ele tenta ensinar deve ser e estar adequado ao estado cognitivo do aluno. Para tanto, o professor dispōe de meios, métodos e/ou procedimentos alternativos que lhe permitem adaptar as condiçōes existentes - recursos físicos e intelectuais - às capacidades e potencialidades dos estudantes. Desta forma, tem-se aqui fundamentado o $3{ }^{\circ}$ componente dos planos de unidade - as estratégias ou padrōes de comportamento docente, que visam a otimizar a situação de aprendizagem.

Nosso último passo na execuçãoa dos planos de unidade foi o de selecionar instrumentos de avaliação. O que nortoou a especificação da avaliação foi a consciência de que, para saber-se se uma experiência oferecida ao aluno(ou se a estratégia utilizada pelo professor surtiu o efeito dese jado) atingiu seu objetivo, ou seja, se a experiência pode ser considerada como aprendizagem (dado que o aluno atingiu o domínio), tem-se que proceder à avaliação específica de cada objetivo da unidade.

Para identificar se esse ensino cumpriu a sua condição essencial - de atividade intencional dirigida para a aprendizagem - realizamos um conjunto de tarefas de avaliação, partindo do princípio de que esta consiste em um con junto de procedimentos sistemáticos para verificar o alcance dos objetivos educacionais que nortearam a unidade. Tal situação, segundo CASAGRANDE (1985) se organiza para proporcionar aos aprendizes "experiências de aprendizagem significativas e relevantes'

Incorporamos a seguir os objetivos de aplicação, por julgarmos que seria de suma importância que o aluno vivesse essas experiências na sua extensão real e não apenas obtivesse os conhecimentos em sala de aula ou através de leituras.

Os objetivos de aplicação visam a proporcionar experiências de aprendizagem mais eficazes, pois são mais próximas da situação real e, por isso, servem melhor ao desenvolvimento da capacidade de solucionar problemas práticos.

Tais objetivos, incorporados ao plano de ensino da unidade, foram baseados em TYLER (1978). Segundo ește autor, a expressão "experiências de aprendizagem' refere-se à interação entre aluno e condições exteriores do ambiente, às quais ele pode reagir. A aprendizagem do comportamento efetivo do estudante, ou seja, a aplicação do seu aprendizado, é expresso pelo autor como: "este aprende o que ele mesmo faz, não o que faz o professor".

Para a elaboração dos objetivos de aplicação, partimos da idéia de que o aprendizado decorre da participação ativa do educando, em situação organizada intencionalmente para facilitar essa aprendizagem; acreditamos que o que determina a produção efetiva desse aprendizado, é a experiência vivida em contato com a situação real, e não somente nos livros, materiais didáticos, recursos áudio-visuais, laboratórios de "faz de conta" e outros meios a que são expostos os estudantes.

$\mathrm{O}$ docente pode proporcionar uma experiência educacional, criando o ambiente e criando a situação de modo a estimular o tipo de reação desejada (TYLER,1978). Essas são as experiências de aprendizagem, definidas por FILOMENO (s.d.), como situaçōes criadas pelo professor para colocar 0 aluno em relação dinámica com a matéria ou conteúdo.

No que se refere ao nível de aplicação, elaboramos 17 objetivos originários e pertinentes aos de conhecimento. Estes foram propostos para 42 alunos. Distribuímos os objetivos de aplicação, com roteiro de tarefas a serem efetuadas e avaliadas no transcorrer do estágio: foram implementadas pelo professor as condiçōes necessárias para a execução das tarefas propostas; solicitamos de cada aluno a exe- 
cução dessas terefas; estas, foram condicionadas aos objetivos cognitivos (de aplicação) pertinentes ao assunto; simultaneamente à cobrança, fizemos uma avaliação do desempenho do aluno, na parte prática do curso.

Objetivos de síntese foram considerados na 3. etapa, partindo-se dos seguintes pressupostos: segundo BLOOM et alii, (1972), a palavra síntese significa a união das partes em um todo; é o processo de trabalhar com as partes e combiná-las a fim de que formem uma configuração (um sentido) não percebida antes.

Com a intenção de facilitar para que os alunos formem essas configurações de um campo do saber é que desenvolvemos os objetivos de síntese, englobando os conhecimentos e aplicações anteriormente adquiridos. Estes se referem aos comportamentos que mostram competência do aluno, para tomar as par- tes ou elementos e organizá-los num todo ordenado e lógico.

Elaboramos 14 objetivos no que se refere ao nível de síntese, provenientes dos objetivos cognitivos e de aplicação. Estes foram distriburdos para 42 alunos.

As notas obtidas por 68 alunos, neste estudo, no pré (coluna A) e no pós-teste (coluna B), são apresentadas na Tabela 1. Trabalhamos com a variável $d$ corresponde à diferença de escores obtidos no pós (B) menos no pré (A) teste, ou seja $d=(B-A)$.

Encontramos a média $d=6,0$ e desvio padrão $\mathrm{S}=0,7$ com um intervalo de confiança que variou entre 5,83 /_- - - $/ 6,17$.

Notamos que, neste estudo, o intervalo de confiança é menor que aquele obtido no estudo de 1983, com valores oscilando bem acima do valor zero, ou seja, fortalecendo bastante a validade da hipotese.

Tabela 1

NOTAS OBTIDAS PELOS ALUNOS (NIVEL DE COMPETÊNCIA) NO PRÉ E PÓS-TESTE.

\begin{tabular}{c|c|c|c|c|c|c|c}
\hline Aluno & $\begin{array}{c}\text { Pré-Teste } \\
\text { (A) }\end{array}$ & $\begin{array}{c}\text { Pós-Teste } \\
(\mathrm{B})\end{array}$ & $\begin{array}{c}\text { Diferença } \\
\mathrm{d}=(\mathrm{B}-\mathrm{A})\end{array}$ & $\begin{array}{c}\text { Aluno } \\
\text { Pre-Teste } \\
\text { (A) }\end{array}$ & $\begin{array}{c}\text { Pós-Teste } \\
(\mathrm{B})\end{array}$ & $\begin{array}{c}\text { Diferença } \\
\mathrm{d}=(\mathrm{B}-\mathrm{A})\end{array}$ \\
\hline & 1,8 & 7,8 & 6,0 & 35 & 3,9 & 9,3 & 5,4 \\
2 & 3,1 & 7,9 & 4,8 & 36 & 3,9 & 9,2 & 5,3 \\
3 & 3,1 & 8,5 & 5,4 & 37 & 3,5 & 9,1 & 5,6 \\
4 & 2,9 & 7,1 & 4,2 & 38 & 1,4 & 8,0 & 6,6 \\
5 & 2,0 & 8,5 & 6,5 & 39 & 1,9 & 7,8 & 5,9 \\
6 & 4,5 & 9,5 & 5,0 & 40 & 2,5 & 8,5 & 6,0 \\
7 & 0,8 & 6,5 & 5,7 & 41 & 1,3 & 8,5 & 7,2 \\
8 & 1,2 & 7,0 & 5,8 & 42 & 3,3 & 9,5 & 6,2 \\
9 & 1,0 & 7,5 & 6,5 & 43 & 0,8 & 8,0 & 7,2 \\
10 & 3,7 & 9,5 & 5,8 & 44 & 0,4 & 8,0 & 7,6 \\
11 & 3,9 & 9,5 & 5,6 & 45 & 0,8 & 7,5 & 6,7 \\
12 & 1,8 & 8,0 & 6,2 & 46 & 1,7 & 8,0 & 6,3 \\
13 & 1,0 & 8,0 & 7,0 & 47 & 1,0 & 7,5 & 6,5 \\
14 & 3,1 & 9,0 & 5,9 & 48 & 2,0 & 7,8 & 5,8 \\
15 & 1,6 & 8,0 & 6,4 & 49 & 0,8 & 8,2 & 7,4 \\
16 & 1,6 & 7,5 & 5,9 & 50 & 0,8 & 7,9 & 7,1 \\
17 & 3,5 & 9,5 & 6,0 & 51 & 0,8 & 7,5 & 6,7 \\
18 & 1,6 & 8,0 & 6,4 & 52 & 2,1 & 8,0 & 5,9 \\
19 & 0.8 & 7,8 & 7,0 & 53 & 2,1 & 8,9 & 6,8 \\
20 & 2,7 & 8,0 & 5,3 & 54 & 1,0 & 9,1 & 8,1 \\
21 & 1,2 & 7,5 & 6,3 & 55 & 1,0 & 8,0 & 7,0 \\
22 & 2,5 & 7,9 & 5,4 & 56 & 1,7 & 8,1 & 6,4 \\
23 & 3,9 & 9,5 & 5,6 & 57 & 2,5 & 7,9 & 5,4 \\
24 & 2,7 & 8,0 & 5,3 & 58 & 3,1 & 9,0 & 5,9 \\
25 & 2,0 & 8,1 & 6,1 & 59 & 2,5 & 8,2 & 5,7 \\
26 & 2,0 & 8,0 & 6,0 & 60 & 3,3 & 8,1 & 4,8 \\
27 & 2,0 & 8,2 & 6,2 & 61 & 1,7 & 8,9 & 7,2 \\
28 & 1,6 & 7,8 & 6,2 & 62 & 0,4 & 7,0 & 6,6 \\
29 & 1,2 & 7,5 & 6,3 & 63 & 1,9 & 8,0 & 6,1 \\
30 & 2,5 & 7,8 & 5,3 & 64 & 4,6 & 9,5 & 4,9 \\
31 & 2,0 & 7,9 & 5,9 & 65 & 0,8 & 8,2 & 7,4 \\
32 & 2,0 & 7,0 & 5,0 & 66 & 3,1 & 8,1 & 5,0 \\
33 & 2,0 & 8,0 & 6,0 & 67 & 4,8 & 9,1 & 4,3 \\
34 & 2,0 & 8,1 & 6,1 & 68 & 3,3 & 8,9 & 5,6 \\
\hline
\end{tabular}


Pudemos concluir que o investimento do tempo do professor no planejamento do curso, seria compensado com os resultados que se podem obter.

Pudemos concluir, ainda neste estudo que a utilização da abordagem de ensino para competência aumenta o rendimento (expresso em escores) do ensino até então realizado. Os resultados mostraram que houve grande eficiência no processo de ensino.

Observamos também durante o desenvolvimento deste estágio do trabalho, a vantagem de que é possível aos proprios alunos avaliarem seu rendimento.

\section{REFERÊNCIAS BIBLIOGRÁFICAS}

1 BLOOM, B.S. Leaming for mastery. Evaluation Comment Los Angeles, 1 (2): 28-32, May 1968.

2 BLOOM, B.S. et alii Tarinomia de objetivos educacionais: domínio cognitivo. Trad. Flávia Maria Sant'Anna. Porto Alegre, Globo, 1972. 179p.

3 BLOOM, B.S. Handbook on Formative and Stormative of Students Learning. New York, McGraw-Hill, 1971.

4 CARON-RUFFINO, M. Categoria de objetivos orientando instromento de avaliação em Enfermagem, 1985, 10p. mimeogr.
5 CARON-RUFFINO, M. Desenuolvinento de planos de unidades de ensino para consecucto de objetivos educacionais em enfermagem, 1986, 18p.

6 CASAGRANDE, L.D.R. Reforma escolar e didárica: exploração do conceito ensino. Ribeirão Preto. Faculdade de Filosofia, Ciências e Letras de Ribeirão Preto, Departamento de Psicologia e Educação. 1973. 101p. tese dout.

7 - _ . "O quadro conceitual de won curriculo". In: SEMINÁRIO DA PRÁTICA DE ENFERMAGEM E O CURRICULO DE GRADUAÇÃO, Ribeirão Preto, 1985 ANAIS... Ribeirão Preto, 1985 p. 87-99.

8 FILOMENO, A. Seleçð̃o de experiência de aprendizagem: sistema de treinamento didático de professores universitários. Rio de Janeiro, NUTES/UFRJ/CLATES/OPAS. s.d.

9 FONTANIVE, N.S. Modelo de aprendizagem para o domínio de Benjamin Bloom: Uma experiência de utilização no Instituto de Ciências Biomódicas da UFR. Tecnol. Educ., Rio de Janeiro, 9 (35): 27-36, 1980

10 ROSCHKE, M.A.C. Elaboração do cronogrona de won Curso: sistema de treinamento didático de professores universitários. Rio de Janeiro. NUTES/UFRJ/CLATES/OPAS, s.d.

11 TYLER, R.W. Princípios básicos do currículo e ensino. Trad. de Leonel Vallandro. 5 ed. Porto Alegre, Globo, 1978. p.57. 